\title{
BUILDING ENERGY CERTIFICATION SYSTEM: APPLICATION TO A BUILDING IN LISBON AND PATHS TO A FUTURE ENHANCED SCHEME
}

\author{
Guilherme Carrilho da Graça ${ }^{12} \quad$ Pedro Nunes $^{1 *} \quad$ Maria Lerer $^{2}$ \\ 1 University of Lisbon, DEGGE, Campo Grande, Edifício C8, 1749-016 Lisbon, Portugal, \\ 2 NaturalWorks, Lisbon \\ *Corresponding author. E-mail: pmnunes@fc.ul.pt
}

\begin{abstract}
Energy efficiency in buildings is of particular importance in the pursuit of international objectives in the area of climate and energy, as it is a sector that represents approximately $40 \%$ of the total primary energy demand [1], with strong growth prospects in absolute consumption. In Portugal, the implementation of the Energy Certification System and Indoor Air Quality (SCE) [2] [3] [4] is an important step in the promotion of energy efficiency and achievement of the national targets regarding the emission of greenhouse gases. This work presents the application of the SCE system to a large office building, the Lisbon City Hall. In the context of the energy audit that was performed, different energy optimization scenarios were defined and analyzed in a cost-benefit perspective. Emphasis is placed on the calibration of the building thermal simulation model (EnergyPlus [5]) and its results. Based on this application of an energy certification code, an examination of the principles that underlie these systems is performed, resulting in a qualitative reflection on the limitations of the SCE system and opportunities for its improvement.
\end{abstract}

Introduction

The introduction, in 2006, of the SCE system in Portugal is the result of the transposition into national law of an European Union directive [6] This directive defines as an objective to reach by all the member states the adoption of measures that ensure, maintaining the comfort levels (or raising them), a reduction in the energy consumption by buildings. The guidelines for achieving these improvements are stated in the directive and consist in adopting a common methodology to verify the energy performance of buildings; define minimum levels of energy efficiency applied to new buildings and existing buildings that are submitted to large retrofitting; creation of energy certification schemes; mandatory periodical inspections for boilers and HVAC systems.

The SCE system was progressively introduced in Portugal in different phases between July 2007 and January 2009, and is now fully operational for about two and a half years. There are two main laws that support the application of this system: RCCTE [4] and RSECE [3]. RCCTE applies to residential and small service buildings ( $<1.000 \mathrm{~m}^{2}$ of net floor area) equipped with HVAC systems under 25 $\mathrm{kW}$ of thermal power. RSECE applies to big service buildings $\left(>1.000 \mathrm{~m}^{2}\right)$ and to small 
buildings equipped with HVAC systems with more than $25 \mathrm{~kW}$ of power. The Lisbon City Hall has approximately $5.400 \mathrm{~m}^{2}$ of floor area, therefore it is within the scope of RSECE.

Under RSECE, the overall energy performance of a building is summarized by a specific indicator of primary energy consumption, the Energy Efficiency Index $(E E I)$, in $\mathrm{kgoe} / \mathrm{m}^{2}$ year. There are several types of EEl:

- EElstANDARD - Calculated value, based on standard conditions of use, defined according the typology (e.g., schools, hotels, etc.) of the building. These standard conditions consist in normalized schedules of occupation, lighting and equipment loads;

- $E E I_{\text {REF }}$ - Reference limit according to the typology;

- EEl REAL, INVOICES - Calculated by simple analysis of the last three years building energy consumption invoices (including climate control consumptions);

- EElreal, simulation - Corresponds to EEI obtained through dynamic thermal simulation of the building using the real conditions of use.

According to the value of these indexes, the building may have to undergo an energy rationalization plan (ERP), as shown in Figure 1. The parameter EEISTANDARD is used in the end of the certification process to define the building energy certification rating.

Regarding indoor air quality standards, the current RSECE states that new buildings must ensure minimum air change rates, which vary depending on the number of occupants, area and space typology. The indoor airflow velocity cannot exceed $0.2 \mathrm{~m} / \mathrm{s}$, to ensure conditions of comfort to the occupants. It is also required the compliance with the maximum concentrations of certain pollutants, as well as microorganisms and radon.

This work explains the general methodology of the SCE/RSECE system, applied to the energy certification of an existing building, the Lisbon City Hall. Surveys were conducted and documentation consulted in order to characterize as much as possible all aspects related to the building energy demand (building construction and geometry, HVAC,

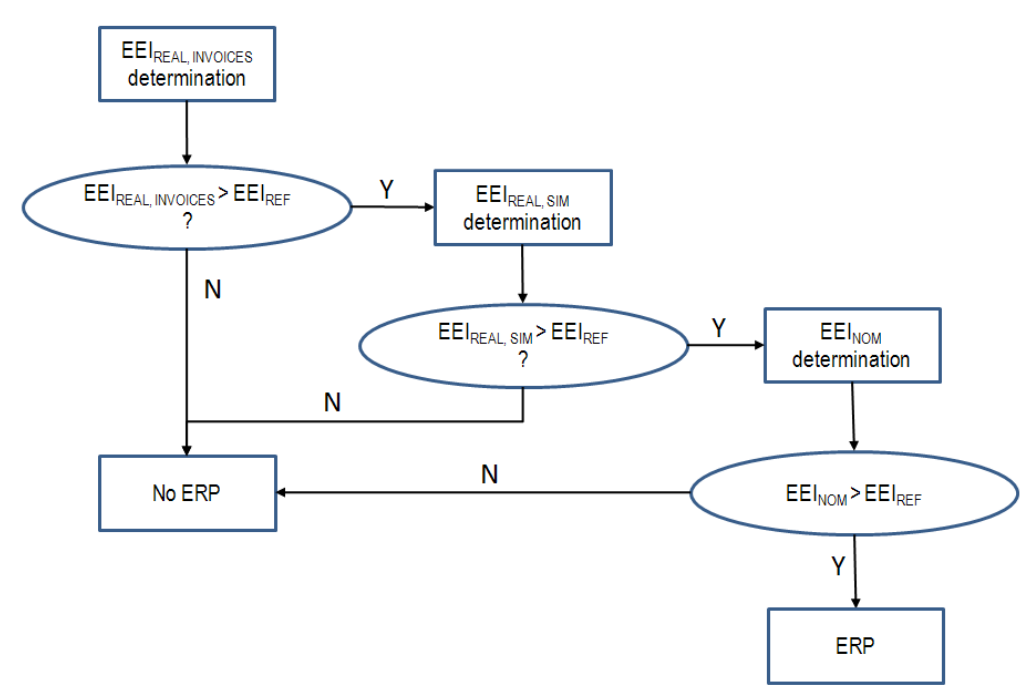

Figure 1 - Definition of the need to submit an existing building to an ERP in the SCE system 
lighting, appliances, occupation and habits of use of the building). Different optimization energy scenarios were defined and simulated. The indoor air quality component of the certification process was not performed, because this work is centered in energy issues. The surveys were made by visits to the building along a period of two months.

Based on this application of an energy certification code, an examination of the principles that underlie these systems is performed, resulting in a qualitative reflection on the limitations of the SCE system and opportunities for its improvement.

\section{Dynamic thermal simulation}

Given the current environmental constraints in energy use and global economic aspects, energy consumption is a primordial key in the design and use of new buildings and rehabilitation of existing buildings. Decisions taken in these phases, and especially in the project phase, are crucial in the thermal performance of buildings and signify important energy savings and also costs (Figure 2). It is therefore important to use a thermal dynamic computer simulation tool to predict the impact of different energy systems and building design options. In the present context, this simulation model will also be used to verifify the compliance with building energy regulations, in this case RSECE.

The thermal simulation package used in this work was U.S. DOE's Energy Plus (E+), v3.1 [5], which is compliant with ASHRAE 1402004 standard method. Because this tool lacks a graphical user interface, that can be very important to model buildings with a complex geometry, DesignBuilder v2 [7] was used in certain steps of the creation of the model.

Two sets of building simulations were performed: in real conditions of use; in standard conditions of use. Measures of energy optimization were included in simulations, separately or in conjunction. Their applicability was always analyzed in a cost-benefit perspective.

\section{Case study}

This section describes the methodology used

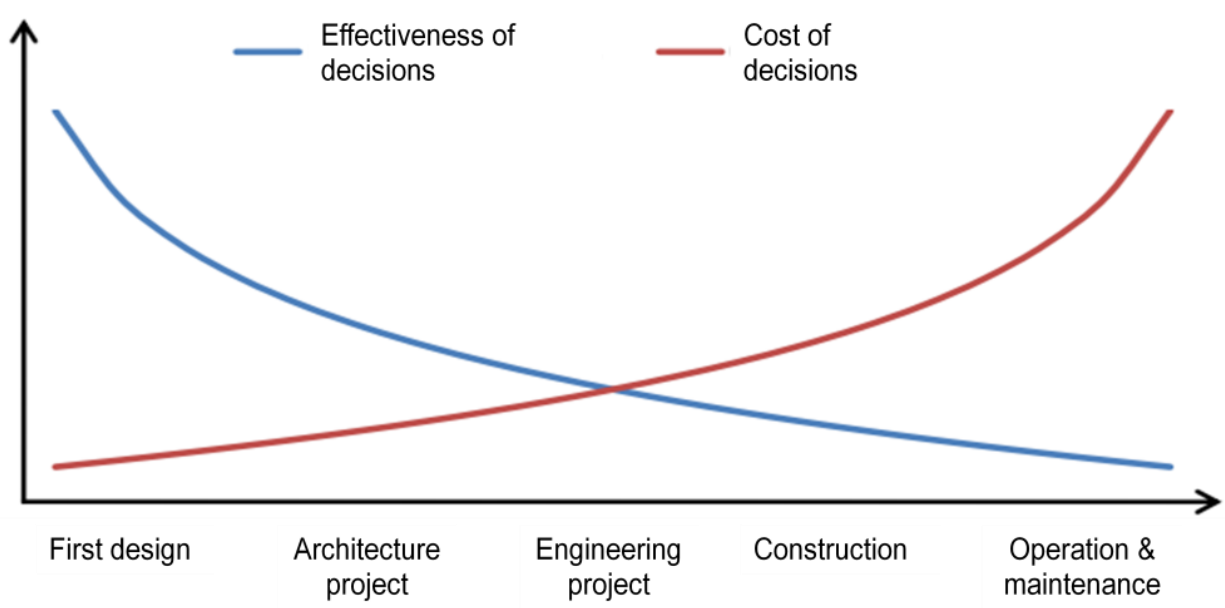

Figure 2 - Costs of decision and its impact on the energy use in a building along its life cycle (adapted from [14]) 
in the process leading to the Energy Certification of the building of Lisbon City Hall. The steps of the process were, in order:

- Data collection (e.g., energy bills, architecture plans, type of construction, building use, equipment installed);

- Setup of thermal simulation model, inputting into EnergyPlus all the data collected, and calibration ofthe model;

- Setup of the standard simulation model, i.e., using the real model of the last step, changing the schedules and densities of people and equipment to comply with RSECE directives;

- Run the simulations for the energy optimization scenarios, for the real simulation and standard simulation models.

\section{Description of the building}

The building is located in a geographic location characterized by a Mediterranean temperate climate, where the cold season is associated with the rainy season. Winters are characterized by mild temperatures due to the influence of the sea in the atmospheric temperature. Summers by the same motive are relatively cool, and dry, due to centers of high barometric pressure. Weather data used in the simulation is representative of a typical year in Lisbon [8]

The case study is a large services building located in the historical downtown of Lisbon (Figure 3), near the Tagus river, with the main façade oriented WSW. The original building was constructed after the 1755 earthquake, but in 1863 there was a severe fire that damaged most of the original building, so a new building was erected in the same site. The current building has around 130 years and a gross area of $6.000 \mathrm{~m}^{2}$ distributed by 4 floors and provides services to the general public, municipal meetings and offices to around a staff of 100 people.

\section{Construction}

Although it was not possible to consult documents with specific information about the constructive solutions used in the building, it is safe to assume that, mostly, its walls are of stone masonry tout-venant type (stone of various sizes resulting from waste mortared with clayey material). This is a typical construction from late XIX century, with massive and thick exterior walls (approximately $1.0 \mathrm{~m}$ ). Interior partitions can reach $0,5 \mathrm{~m}$ thickness. Clearly, the building has high thermal inertia.
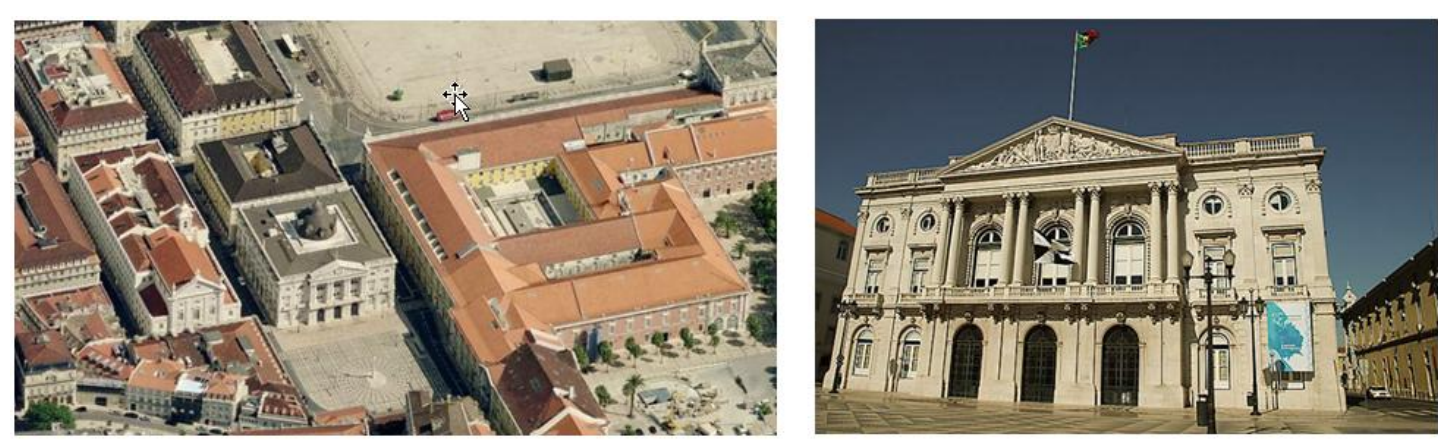

Figure 3 - The Lisbon City Hall building 
Single glazing wood frame windows occupy less than $50 \%$ of the façade area. Shading is manual (internal rolling curtains).

\section{HVAC system}

The building has, since 1997, a centralized HVAC system consisting of:

- Two fresh air treatment units, total $9.300 \mathrm{~m}^{3} / \mathrm{h}$ (fixed);

- A chiller (65 kW) and a heat pump (73 kW) air-water two tubes systems;

- 26 VRV type HVAC units with the condensers installed in the rooftop and the evaporators (61) inside the offices. Control of this system is done automatically in a central unity that can be overridden by manual controls installed in the offices.

\section{Lighting}

A survey was carried out as detailed as possible to identify the discrepancies between the ten year old lighting and the existing lighting system. There were some changes, particularly in terms of lamps used, which in some cases already are of low consumption, something that the project did not include. It was also, through inquiry, constructed the profiles of use of lighting, in time and in fraction of the total power installed. A significant fraction of the lighting, particularly in offices, is done by fluorescent tubes behind ceiling moldings. Given the architectural value of the spaces, there is also a significant fraction of light carried by incandescent lamps installed in the chandeliers (Figure 4). Total lighting power installed is $12 \mathrm{~kW}$ and the average lighting power density for the whole building is $10,3 \mathrm{~W} / \mathrm{m}^{2}$.
As in the case of lighting, a survey was carried out to identify the electrical appliances, e.g., office equipment, existing throughout the building. The average equipment power density is $5,52 \mathrm{~W} / \mathrm{m}^{2}$.

\section{Energy bills}

The building does not use natural gas, only electricity. Thus, even the kitchen appliances are exclusively electrical. This means that the only existing energy bill is from the electrical company, EDP. Also there is only one electricity meter for the entire building, so there is no disaggregated information about consumption for different uses, including HVAC systems.

The energy consumption survey was based on 36 monthly electricity bills (representing the last three years). The average yearly consumption is 559 MWh/year, which corresponds to $104 \mathrm{kWh} / \mathrm{m}^{2}$.year. As expected in a services building located in a temperate climate, electric consumption during Summer for cooling is higher than in Winter for heating.

Using a conversion factor of electricity to primary energy $\left(F_{p u}=0,00029\right.$ toe $\left./ k W h_{e}\right)$ we

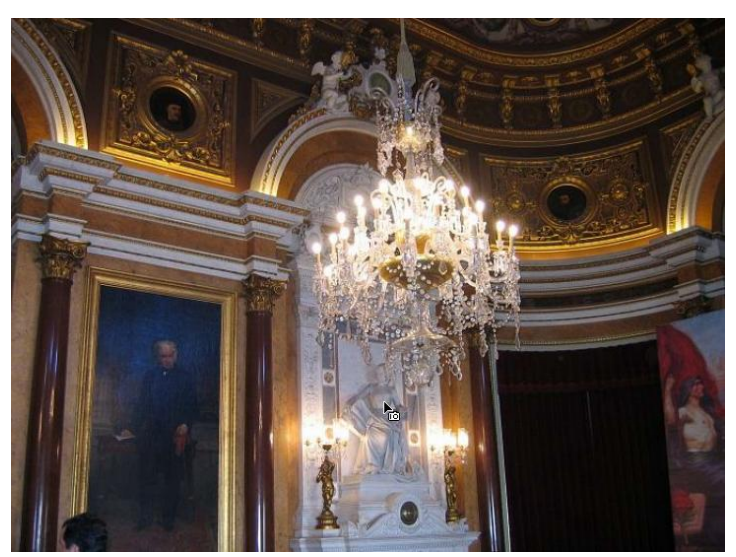

Figure 4 - Example of chandelier in the noble saloon 
can estimate

$$
E E I_{\text {REAL,INVOICES }}=30 \frac{\mathrm{kgep}}{\mathrm{m}^{2} \cdot \text { year }}
$$

\section{Utilization profiles}

Detailed survey by questionnaire was performed in order to identify the building use schedule. From this information, twenty-four hour schedules for weekdays, weekends and holidays were constructed for input into the computational model.

\section{Computational model of the building}

The construction of a simulation model representative of reality is an iterative process, where the analysis of results generates sequential modeling refinements. Figure 5 shows a 3D renderization of the simulation model. The projected shadows correspond to the occlusion of the sun by adjacent buildings at $14 \mathrm{~h} 00$ of $15^{\text {th }}$ December. As a result of: geometry, orientation, glazing surface, HVAC installed, internal loads, etc., the building model was divided into 19 thermal zones.

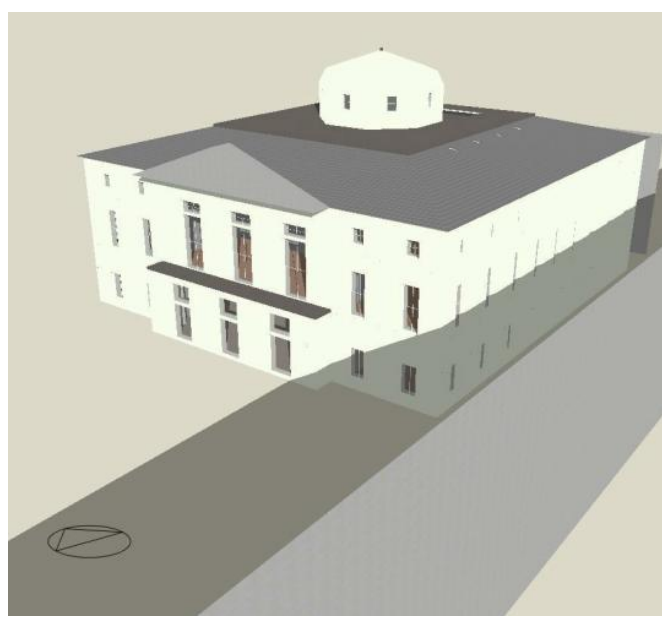

Figure 5 - Visualization of the 3D model (from SW)
All the relevant data collected in the surveys was introduced in the model. Infiltration of outside air was defined according the existence or not of mechanical fresh air supply in the spaces and level of envelope tightness. The HVAC system was modeled according the HVAC project that was supplied by the building manager. The internal temperature setpoints used were: $21^{\circ} \mathrm{C}-25^{\circ} \mathrm{C}$ (Winter and Summer, respectively). Comparison between the simulation results and the energy consumption obtained from the invoices allowed for an estimation of the overall efficiency of the HVAC system.

\section{Model calibration}

Calibration of the simulation model is an iterative process of adjustment whose goal is to obtain predicted energy consumption values that are similar to the energy bills (invoices). In this case (where there are no measurements of direct parameters such as temperature in thermal zones, consumption and efficiency of the HVAC system), the variable evaluated in the calibration of the model is the total predicted electricity consumption. The process can lead to a series of adjustments of various parameters of the model. Under RSECE, a model is considered calibrated if the total predicted electricity consumption is within $\pm 10 \%$ of the total consumption data from the energy bills. An additional requirement was adopted: predicted monthly consumption must be within $\pm 15 \%$ of the average monthly data from the energy bills.

Initial simulations showed that the two requirements were not totally fulfilled. Thus, corrections to the initial data introduced in the model had to be done such as a more detailed assessment of the building usage 
schedule. One example of these adjustments is the occupation of offices until late hours in the evening that happens in a typical week. Although this type of occupation has no pre defined pattern, it leads to lighting energy consumption until $23 \mathrm{~h} 00$. The calibration process also refines the prediction of real COP of HVAC systems, i.e., overall COP including losses in distribution and loss of efficiency of equipments due to usage.

Results of calibration are shown in Figure 6. Typical COP of HVAC systems is approximately 2,5 and the overall COP determined was 1,5 (a $40 \%$ reduction). For the total yearly energy consumption there is a $3 \%$ difference, with all months within the $15 \%$ tolerance criteria defined.

\section{Simulation in real conditions of use}

The results of the thermal simulation using real conditions are summarized in Table 1. The total yearly predicted energy consumption is $544,5 \mathrm{MWh}$ (total value of the first column).
Table 1 - Annual electric consumptions by type of use

\begin{tabular}{|c|c|c|}
\cline { 2 - 3 } \multicolumn{1}{c|}{} & MWh & share of total \\
\hline Lighting & 297,5 & $54,6 \%$ \\
\hline $\begin{array}{c}\text { Electrical } \\
\text { appliances }\end{array}$ & 57,1 & $10,5 \%$ \\
\hline Heating & 56,3 & $14,0 \%$ \\
\hline Cooling & 83,9 & $17,8 \%$ \\
\hline
\end{tabular}

From these values, an EEI can be calculated:

$$
\text { EEI REAL,SIMULATION }=30 \frac{\mathrm{kgep}}{\mathrm{m}^{2} \cdot \text { year }}
$$

Annual profiles of heat and cool demand are represented in Figure 7

It follows from this results that lighting is responsible for the largest share of the total electrical consumption in the building $(54,6 \%)$. Offices and circulations share $34 \%$ and $27 \%$ respectively of this consumption. The HVAC system (including fans) accounts for less than a third of the overall building consumption.

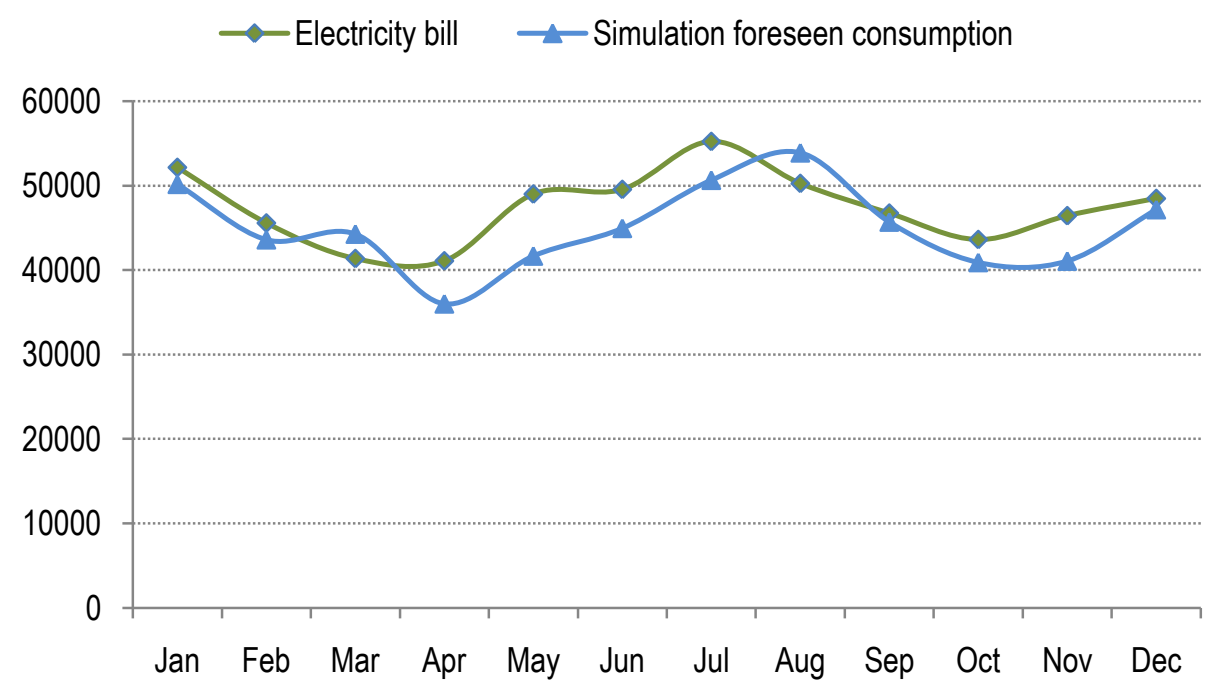

Figure 6 - Evolution along year of the foreseen consumption by the simulation and the electricity consumption billed 


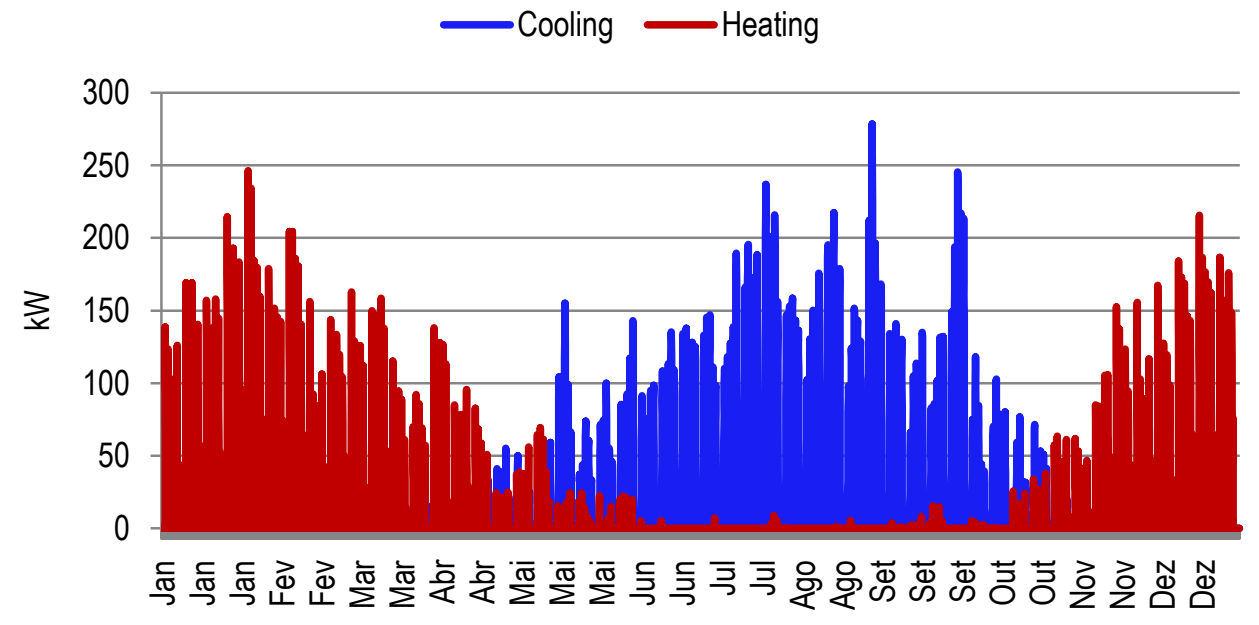

Figure 7 - Annual profile for heating and cooling demand

These figures fit the norm for this type of buildings.

\section{Simulation in standard conditions}

As discussed above, the RSECE/SCE system analyses the energy performance of a building using a methodology that is independent of building use. The goal of the system is to be able to compare the energy efficiency of different buildings that can have in practice very different profiles of use, thus otherwise of difficult comparison. These standard conditions of use are a set of profiles of occupancy, lighting and equipment, which varies according to the building type. These standard profiles are listed in the regulation.

For the present building, the standard conditions are $15 \mathrm{~m}^{2} /$ occupant (real: 26 $\mathrm{m}^{2} /$ occupant), $5 \mathrm{~W} / \mathrm{m}^{2}$ of electrical appliances (real: $5,5 \mathrm{~W} / \mathrm{m}^{2}$ ), fresh air ventilation rates and the schedules for occupancy, equipment and lighting. The lighting load that is used in the simulation is not predefined in the regulation: the actual installed should be used in the simulation.
Finally, the effects of climate variation between different locations in the country are eliminated through the application of correction factors for winter and summer heating and cooling demand.

Maximum standard heating and cooling demand are defined as function of the climatic region where the building is located. For the present case, these limits are $51,5 \mathrm{kWh} / \mathrm{m}^{2}$ and $32 \mathrm{kWh} / \mathrm{m}^{2}$, respectively.

The results of the simulation in standard conditions are summarized in Table 2. One should note that lighting consumption is much

Table 2 - Results of simulations in standard conditions of use

\begin{tabular}{|c|c|c|}
\cline { 2 - 3 } \multicolumn{1}{c|}{} & MWh & $\begin{array}{c}\text { Difference } \\
\text { regarding real } \\
\text { conditions }\end{array}$ \\
\hline Lighting & 182,8 & $-38,6 \%$ \\
\hline $\begin{array}{c}\text { Electrical } \\
\text { appliances }\end{array}$ & 51,2 & $-10,3 \%$ \\
\hline Heating & 65,0 & $+15,4 \%$ \\
\hline Cooling & 75,6 & $-9,9 \%$ \\
\hline
\end{tabular}


lower in standard conditions due to the lower usage profile, which is more reasonable than the real profile (operation of offices until $23 \mathrm{~h} 00$, etc.); consumption for heating is higher in standard conditions because of less heat generated by lighting. The same is conversely true for cooling demand.

The value of the EEISTANDARD is:

$$
\text { EEI } I_{\text {STANDARD }}=20,5 \frac{\mathrm{kgoe}}{\mathrm{m}^{2} \cdot \text { year }}
$$

Since for this type of building the reference maximum value that is legislated it is 15 $\mathrm{kgoe} / \mathrm{m}^{2}$.year, it follows that, for this case, the implementation of an energy rationalization plan is mandatory. This plan must consist of energy saving measures that have a simple payback period inferior to 8 years, determined by simulation or other method for the real conditions of use of the building. Energy class of the building is $C$, in a scale from $A+$ (the better) to $G$ (the worst) (Figure 8).

\section{Energy optimization measures}

One objective of this work consists in identifying and analyzing potential measures to improve energy efficiency of the building, associated costs and energy savings. The measures analyzed were: improved lighting,

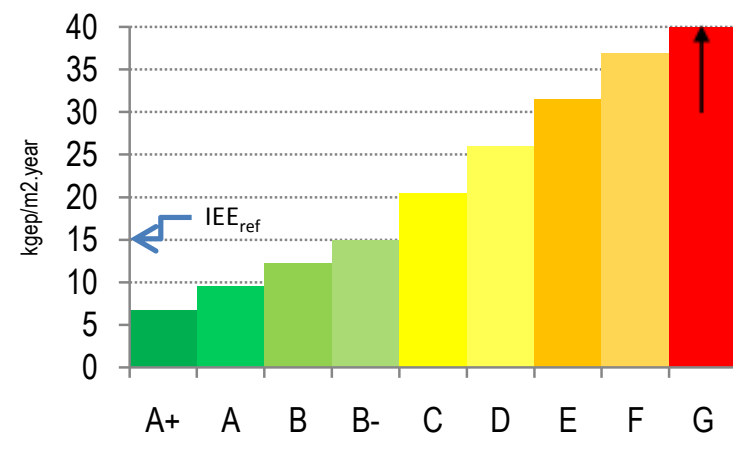

Figure 8 - Energy classes for the building installation of photovoltaic (PV) panels, installation of a geothermal heat pump.

\section{Lighting scenario}

In a perspective to reducing the energy bill, clearly the area where there is greater potential for intervention is in the lighting systems (see Table 1). Identification of the locations where it is possible to intervene obeys to three criteria: compatibility between possible intervention and the character of the space (first criteria because there are special areas with inefficient lighting systems where intervention is not possible for architectural reasons); existing lighting density; share of the zone in the total consumption.

A scenario of low consumption lighting ( $\mathrm{LCL})$ was defined using the following measures:

- Substitution of incandescent lamps by compact fluorescent lights (CFL) with the same total amount of lumens. This is a measure that must be applied given the UE mandated prohibition of sale of incandescent lighting bulbs, starting in 2012;

- In offices, it is proposed the elimination of lighting in the false ceiling cavities (indirect light), given high luminous inefficiency of this system (less than $1 / 3$ of the emitted photons reaches the work plan). This is supported by the fact that the offices currently have an illumination density of 20 $\mathrm{W} / \mathrm{m}^{2}$, which is clearly high. It is advisable therefore a lighting solution in a plane directly below the ceiling, allowing a level of brightness in the work plan between 350 and 400 lux. One possibility is the installation of lights suspended on the ceiling or fixtures on the walls. The implementation of such measures leads to a reduction in lighting density to $8 \mathrm{~W} / \mathrm{m}^{2}$, a value already in line with 
modern good practices of energy efficiency. The possibility of installing lamps in the work plan is not dismissed given its greater efficiency;

- Substitution of existing halogen lamps by low consumption alternatives with equal luminous power (in the market there are such lamps with gains in energy efficiency of about $25 \%)$.

A second LCL scenario, LCL2, was defined, which differs from the first scenario in the lighting schedules for the offices that are equal to the occupation schedules. The survey showed that during mealtimes, or in any other case of absence of workers, the lights are not turned off. This second scenario therefore considers that lighting follows the occupation, and its implementation may pass through conscientization of the employees of the importance to turn off the lights when they leave or can be implemented by adoption of motion detectors in the offices. The spaces affected by these measures represent $80 \%$ of total lighting consumption and $44 \%$ of total electrical consumption in the building.

\section{PV scenario}

The roof of the building offers the possibility of installation of a PV system in its south facing portion. The total area available for this installation is approximately $220 \mathrm{~m}^{2}$ with a slope of approximately $11^{\circ}$ and an azimuth of $17^{\circ}$ relative to the south in SE direction. The panels, for architectural reasons, should of course be installed in a plane parallel to the roof (a slope of $11^{\circ}$ penalizes production by approximately $6,1 \%$ when compared with the optimal inclination, which, for Lisbon, is $32^{\circ}$ ). Monocrystalline modules were chosen with a total installed power-peak of about $24 \mathrm{~kW}$.
Simulation showed that the average annual net output would be 31,3 MWh (considering losses in the system due to temperature, wiring and inverter [9]). We considered that the kWh sold to the grid has the same price than the kWh bought (tradeoff).

\section{Geothermal scenario}

The phreatic water level near the river is very high, with a depth of about 3,5 m [10]. Given this proximity to the water it is relevant to study a scenario that replaces the air source heat pumps with geothermal heat pumps (this scenario was called GHP). We considered that the replacement pump has a COP of 4,5 . In the simulations, an effective COP of 3,15 was used, considering already $30 \%$ of losses in distribution network. This means that, for the whole building, the overall COP increases from 1,5 to 1,84 (a $23 \%$ improvement).

This is an equipment to be installed in the basement connected to the existing hydraulic distribution network, replacing the existing heat-pump/chiller. In this study it is considered that the VRV system with fan-coils cannot be connected to this equipment, because of the intrinsic different principle of operation.

\section{Results for real conditions}

Figure 9 shows the results of predicted electrical consumption of the building in real conditions of use. Table 3 shows the annual savings and payback periods calculated.

If one considers the simultaneous adoption of the all optimization scenarios (LCL, PV and GHP) the annual electricity bill decreases by approximately $25 \%$ (€15.794 of savings), with a payback period of 14,8 years. If one considers combination of scenarios LCL2, PV 
and GHP, payback period decreases to 13,5 years.

\section{Results for standard conditions}

The previously defined optimization scenarios were also simulated in standard regulation usage and load conditions (except the LCL2 scenario that implies a change in usage profiles). The LCL2 scenario was replaced by the LCL3 scenario, which is a variant of the LCL scenario with modified lighting density in the dinner room (which is a formal space rarely used but with a very high lighting density, $191 \mathrm{~W} / \mathrm{m}^{2}$ ). Substitution of fiber optic existing illumination by LEDs is proposed in this scenario, which leads to a $2 / 3$ reduction in lighting density. This scenario was not simulated for real conditions of use because, as discussed, this space is rarely used, and the modification proposed would have in real conditions a payback period too much elevated.

Figure 10 summarizes the results obtained (EEISTANDARD for each scenario). These results show that:

- The simultaneous application of scenarios LCL3+PV+GHP results in an improvement in energy class, from $\mathrm{C}$ to $\mathrm{B}$-;

- Overall, EElstandARD improves by $25 \%$ (a decrease in 5,5 kgoe $/ \mathrm{m}^{2}$.year);

- Despite LCL3 having negligible effects on real consumption, it allows for, in standard conditions, an improvement of 0,6 $\mathrm{kgoe} / \mathrm{m}^{2}$.year, $2.9 \%$ in the overall value of the indicator. The additional costs of the intervention is estimated at about $€ 3.000$, and based on these assumptions the payback period for this measure is calculated to be 2,65 years.

\section{Qualitative limitations of the SCE}

The SCE system is meant to promote building energy efficiency. Ultimately its application should result in tangible energy savings compared to what the industry would be without this regulation. However, in SCE's current format there are criteria that have been overlooked that are of special importance in the evaluation of the energy efficiency of the building.

This section presents a qualitative approach to the limitations of the SCE system. A set of possible improvements is discussed. Some of the proposed improvements are already in use in other certification systems, such as LEED [11] or BREEAM [12].

\section{Life cycle analysis (LCA)}

The overall energy impact of a building is more than just its operational energy consumption. For an adequate assessment of the overall impact it is necessary to perform a comprehensive analysis of the energy used in all stages of life cycle of the building. The SCE system is limited to energy consumption during building use, leaving aside the embodied energy in the materials and equipment that results from manufacturing processes, transportation, assembly, decommissioning and recycling. This limitation becomes more severe as the energy efficiency of the building increases, thereby increasing the relative weight of the energy embodied in materials.

Another possible evolution in the certification scheme adopted in Portugal is the extension of its scope to non intrinsic parameters to the building, but important in assessing its energy sustainability in a wider way. In particular, the extent of the certification system to the 


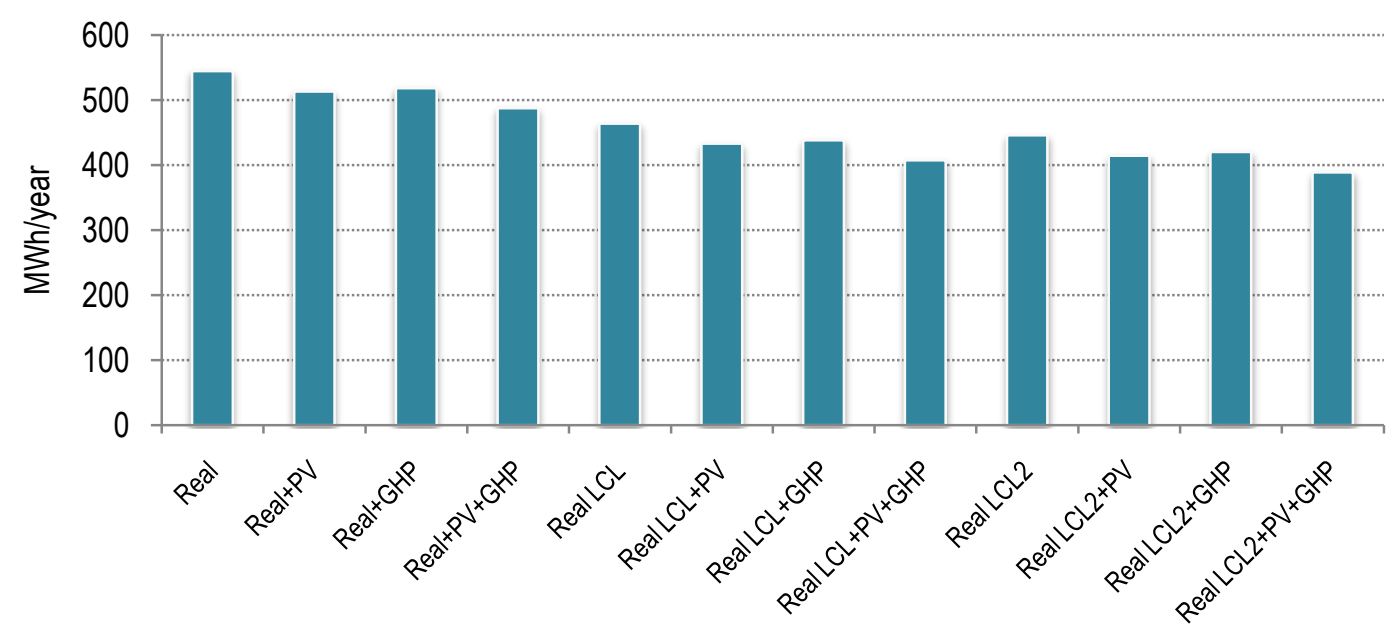

Figure 9 - Net total electrical consumption from the grid for the projected scenarios

Table 3 - Annual savings and payback periods for the scenarios

\begin{tabular}{|c|c|c|c|c|c|c|c|c|c|c|c|}
\cline { 2 - 11 } \multicolumn{1}{c|}{} & $\begin{array}{c}\text { REAL } \\
+\mathrm{PV}\end{array}$ & $\begin{array}{c}\text { REAL+ } \\
\text { GHP }\end{array}$ & $\begin{array}{c}\text { REAL } \\
\text { +PV+ } \\
\text { GHP }\end{array}$ & $\begin{array}{c}\text { REAL } \\
\text { LCL }\end{array}$ & $\begin{array}{c}\text { REAL } \\
\text { LCL+ } \\
\text { PV }\end{array}$ & $\begin{array}{c}\text { REAL } \\
\text { LCL+ } \\
\text { GHP }\end{array}$ & $\begin{array}{c}\text { REAL } \\
\text { LCL+P } \\
\text { V+GHP }\end{array}$ & $\begin{array}{c}\text { REAL } \\
\text { LC2 }\end{array}$ & $\begin{array}{c}\text { REAL } \\
\text { LCL2+ } \\
\text { PV }\end{array}$ & $\begin{array}{c}\text { REAL } \\
\text { LCL2+ } \\
\text { GHP }\end{array}$ & $\begin{array}{c}\text { REAL } \\
\text { LCL2+PV } \\
\text { +GHP }\end{array}$ \\
\hline $\begin{array}{c}\text { Annual } \\
\text { savings }(€)\end{array}$ & 3600 & 2980 & 6580 & 9242 & 12841 & 12194 & 15794 & 11334 & 14933 & 14295 & 17895 \\
\hline $\begin{array}{c}\text { Annual } \\
\text { savings (\% of } \\
\text { consumption) }\end{array}$ & $5,7 \%$ & $4,8 \%$ & $10,5 \%$ & $14,8 \%$ & $20,5 \%$ & $19,5 \%$ & $25,2 \%$ & $18,1 \%$ & $23,8 \%$ & $22,8 \%$ & $28,6 \%$ \\
\hline $\begin{array}{c}\text { Investment } \\
\text { cost (€) }\end{array}$ & 137409 & 31344 & 168753 & 64697 & 202105 & 96041 & 233449 & 73579 & 210988 & 104923 & 242332 \\
\hline $\begin{array}{c}\text { Payback } \\
\text { (years })\end{array}$ & 38,2 & 10,5 & 25,6 & 7,0 & 15,7 & 7,9 & 14,8 & 6,5 & 14,1 & 7,3 & 13,5 \\
\hline
\end{tabular}

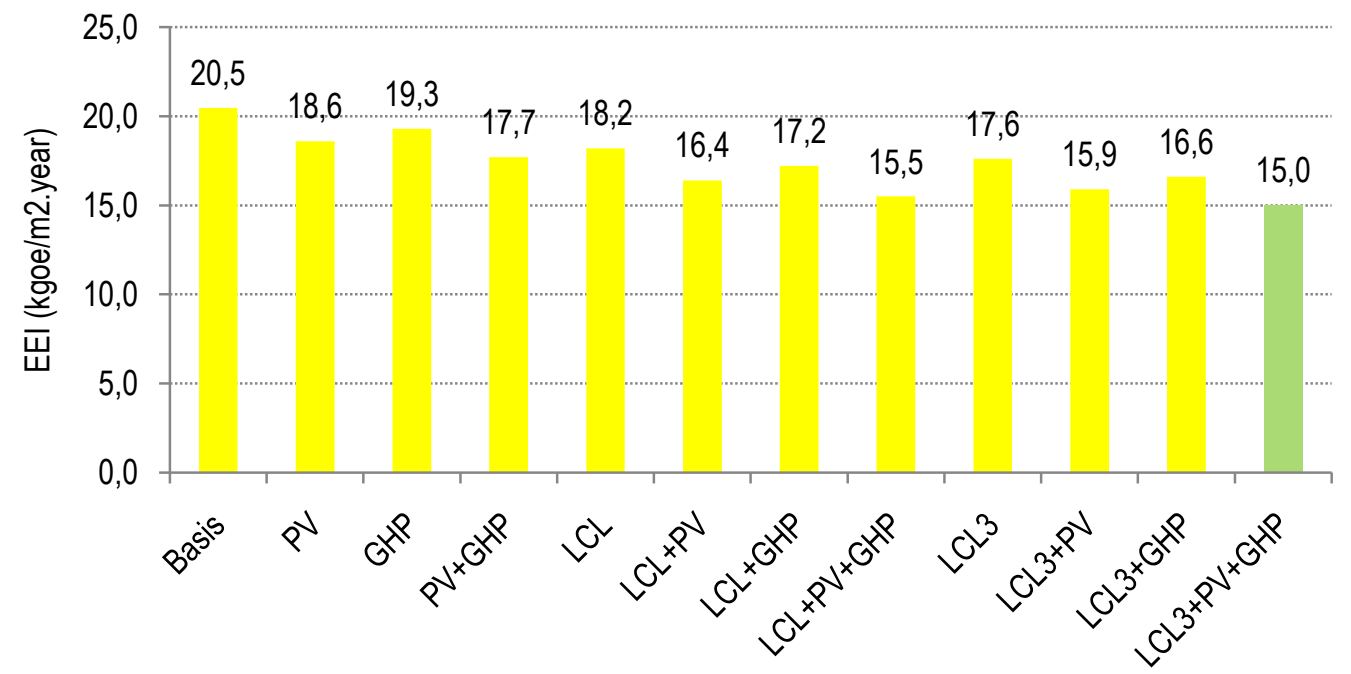

Figure 10 - Evolution of the EEISTANDARD in function of the various scenarios proposed 
energy consumption that is inherent to the average daily commute of the building users. However, since this is not a parameter intrinsic to the building, and changes in accordance with a number of factors (new roads, technological developments in the automotive sector, etc.), its introduction into the energy certification system lacks a careful analysis. American LEED and English BREEAM systems can serve as case studies for this possible evolution of the SCE system.

\section{Limitations to the consumption of renewable energy}

The importance of choosing an appropriate indicator of energy efficiency is critical to the success of any energy certification system. In the current context of limitations of energy consumption at national and international level, such indicator should establish consumption limits booth for fossil and renewable energy. In the current SCE version these limits only apply to energy from conventional sources, with no imposition of maximum consumption of renewable energy. This may, in some cases, allow for inefficient use of renewable resources.

For example, under the SCE system, an inefficient building with high energy consumption can still obtain an $A+$ rating if significant part of its energy consumption is from renewable energy systems incorporated in the building (e.g., PV, solar-thermal). In this context, there may be an inadequate use of a natural resource, which, despite being renewable, must be used sustainably.

\section{Improvement of the EEI}

Given that the purpose of the SCE is to limit overall consumption in the buildings sector (in toe/year or $\mathrm{kWh} /$ year), the units adopted (kgoe/m².year) may appear, in a first instance, appropriate. However, it may be more effective to impose restrictions in terms of occupants rather than per unit of floor area, since most buildings are designed for people. Thus, the proposed indicator would have units of kgoe/occupant.year. A limit may be set on the number of occupants $/ \mathrm{m}^{2}$ to guarantee that buildings which exceed a reasonable density of occupation (function of typology) do not have that excess accounted in the EEI calculation. This type of indicator would impose higher energy standards on houses or services' buildings with low occupancy densities, and thus would prove more effective from an overall sustainability perspective. Finally this indicator is directly proportional to the building energy costs per occupant (as opposed to per square meter in the case of the standard indicator).

We have performed an exploratory exercise with the building studied, which has a relatively low real occupation density of 25,8 m²occupant. This number includes occasional occupants, for example citizens who attend city hall meetings, and therefore it is inappropriate for comparison with other buildings with other types of occupation. For a correct assessment, it is necessary to normalize patterns of occupation. This normalization can be carried out for working weeks of the year on the basis of $8 \mathrm{~h} /$ day on working days (40h/week), generating a correction factor $F c$. This factor will be function of the various types of space utilization, each corresponding to one type of use profile $i$. The expression of the correction factor takes the form

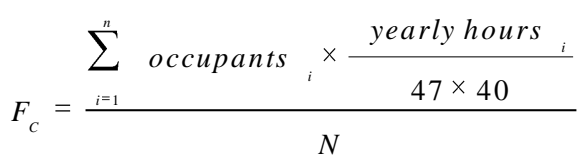


Being:

$$
\text { occupants, - total number of occupants }
$$

with the usage profile $i$;

yearly hours - total number of hours per year that each occupant with real $i$ use profile remains in the building;

$N$ - total number of occupants;

47 - average number of working weeks per year;

40 - number of weekly working hours (8h/day).

Thus, normalized number of occupants in a building is calculated with the expression

$$
\text { occupants }_{\text {normalized }}=F_{C} \times N
$$

Adopting this methodology in the Lisbon City Hall building, which has an occupation of 105 employees during work hours and about 208 occasional visitors per week (for calculations, we used 104 at a time, two times per week,

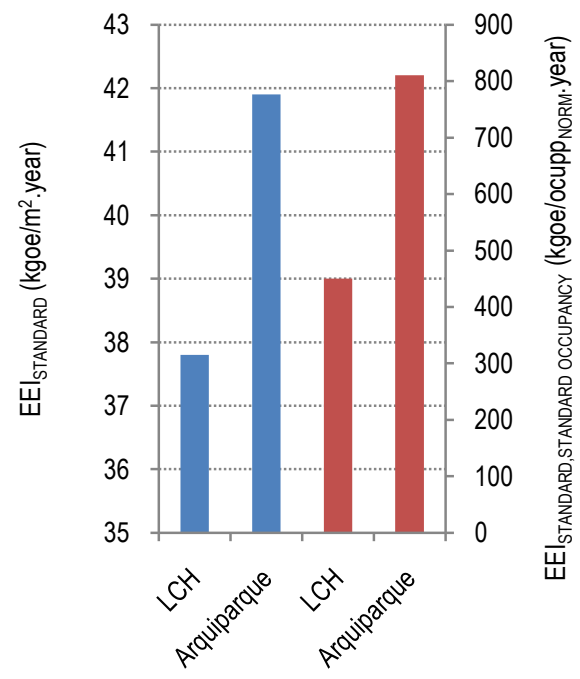

$\square E E I$ standard $\square E E I$ standard per standard occupants

Figure 12 - EEISTANDARD values for the two buildings using same typology
8 h/day), we obtain a normalized value of 145 occupants. Since EEl REAL, INVOICES of the building is $30,0 \mathrm{kgoe} / \mathrm{m}^{2}$ year, we obtain

$$
\begin{aligned}
& E E I_{\text {REAL,OCC }}=30,0 \times \frac{5.398}{145}= \\
& =1.117^{\mathrm{kgoe} / \text { occupant }_{\text {norm }} \text { year }}
\end{aligned}
$$

In order to understand the meaning of this indicator, a comparison with a different building was performed. For this purpose a typical modern office building situated in the outskirts of Lisbon was used (the Arquiparque building, in Oeiras, certified with energy class C [14]).

For comparison of the buildings in standardized conditions, Lisbon City Hall building was simulated for the same typology of Arquiparque. Results for the EEISTANDARD are those presented in Figure 12. The same figure presents also the results using the indicator that is based on occupation density.

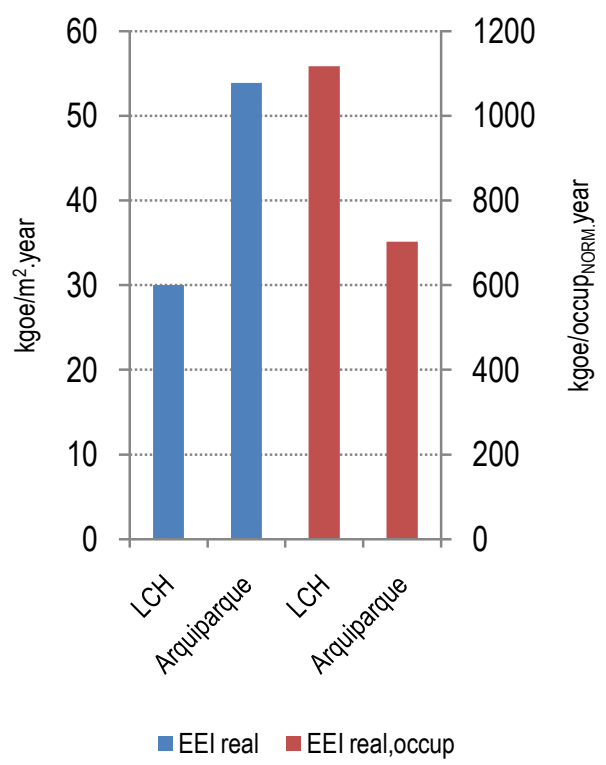

Figure 11 - EEl REAL values for the two buildings in useful footage area basis and in normalized occupational basis 
The relevant parameters for the comparison between the two buildings are summarized in Table 4. Figure 11 presents a comparison of the EEI REAL for the two buildings using the standard and the newly introduced criteria. Despite the difference in typology between the two buildings, the end use type is not fundamentally different as they are both service buildings. Lisbon City Hall building has values of specific consumption per square meter that are substantially lower than the Arquiparque building. However, there is a reversal of this ranking if we use an indicator based on normalized occupation.

Using the EEISTANDARD indicator, the Lisbon City Hall building is rated as being approximately $10 \%$ more efficient than the Arquiparque building (both buildings are in the same energy class, C). Using the EEI REAL, ocC indicator (Figure 11) leads to a different ranking where the Lisbon City Hall building is approximately $37 \%$ less efficient (due to its lower occupation density). So, in terms of annual energy cost per occupant we conclude that that the Arquiparque building is more efficient than the Lisbon City Hall building.

Another useful type of indicator would use occupancy and cost indicators, taking into account energy costs per occupant, rather than primary energy consumption per unit of floor area. An indicator of this type would be advantageous and more intuitive in some sectors, such as services, allowing building owners and management companies to have immediately a clear picture of the energy cost per occupant. The results of the application of this indicator to the two buildings are shown in Table 5. Also in this case the Arquiparque building outperforms the Lisbon City Hall building (as expected).
Table 4 - Relevant parameters of the two buildings for comparison

\begin{tabular}{|l|c|c|}
\cline { 2 - 3 } \multicolumn{1}{l|}{} & LCH & Arquiparque \\
\hline Area $\left(\mathrm{m}^{2}\right)$ & 5.398 & 4.602 \\
\hline Ocupation & 209 & 353 \\
\hline FC & 0,69 & 1,00 \\
\hline Occupants normalized & 145 & 353 \\
\hline $\begin{array}{l}\text { Real occupation density } \\
\text { normalized (m²/occupant) }\end{array}$ & 37,2 & 13,0 \\
\hline Lighting density (W/m²) & 35,3 & 13,3 \\
\hline $\begin{array}{l}\text { Real electrical appliances } \\
\text { density (W/m²) }\end{array}$ & 5,5 & 13,5 \\
\hline $\begin{array}{l}\text { EEl } \\
\text { REAL (kgoe/m².year) }\end{array}$ & 30,0 & 53,9 \\
\hline $\begin{array}{l}\text { EE } \\
\text { (kgoe/occupant oc }\end{array}$ & 1.117 & 703 \\
\hline
\end{tabular}

\section{Extensions and limitations of the SCE}

In the exercise of application of the SCE, we encountered another limitation which can reduce the success in containment of consumption in existing buildings. In the calculation of the energy class and EEI there are parameters that are simulated using

Table 5 - Energy costs per capita for both buildings

\begin{tabular}{|c|c|c|}
\cline { 2 - 3 } \multicolumn{1}{c|}{} & LCH & $\begin{array}{c}\text { Arquiparq } \\
\text { ue }\end{array}$ \\
\hline $\begin{array}{c}\text { Energy costs per } \\
\text { capita } \\
(€ / \text { occupant } \\
\text { earEAL.y }\end{array}$ & 307 & 285 \\
\hline $\begin{array}{c}\text { Energy costs per } \\
\text { capita } \\
(€ / \text { occupant } \\
\text { ear } \text { ear })\end{array}$ & $443 . y$ & 285 \\
\hline
\end{tabular}


conditions defined by regulation (standard conditions), such as: occupation density, equipment density and all schedules. This option distorts the results because, for example, a building with obsolete equipment is not penalized, which is not desirable. On the other hand, an owner or tenant of a building that invests in the latest equipment with state of the art energy performance does not see his building benefited under the current SCE system.

\section{Conclusions}

This work presented the application of the Portuguese energy certification system (SCE) to an historic services building located in the center of Lisbon. Energy consumption of the building was predicted for different scenarios using a computational simulation model calibrated against the available electrical energy consumption bills. Using this application example as a case study for energy rehabilitation of historic buildings, a set of energy optimization scenarios where analyzed. Finally a set of proposal for system improvement where presented and tested.

The results of the calibrated building thermal simulation model showed that:

- Lighting is the largest contributor to the overall energy consumption (55\%);

- The HVAC system is the second largest consumer, with a $31 \%$ share in the total;

- The building as an energy rating of $C$ (on a scale that goes from $G$ to $A+$ ).

- On a monthly basis, the maximum difference between the invoiced and predicted by simulation is always less than $15 \%$;
Using the calibrated thermal simulation model, a set of energy optimization scenarios where analyzed, including: improved lighting, introduction of on site renewable energy production using photovoltaic panels and improving the overall COP of the HVAC system by replacing the existing air sourced heat pump with a geothermal heat pump. If all optimization scenarios are implemented simultaneously, the energy consumption of the building is reduced by approximately $30 \%$ and the energy rating is improved to B(meeting the minimum acceptable level for new buildings). The overall payback of the optimized energy systems is under 14 years.

Our analysis identified the following areas where the SCE system can be improved:

- In the current format of the SCE, the embodied energy in the materials that compose a building is not taken into account. This limitation will became more important with the ongoing improvement in building energy efficiency (that will make material embodied energy more important in the total amount of energy consumed by the building);

- The current regulation does not provide limitations on the consumption of renewable energy in buildings, and particularly its contribution to the energy efficiency index (EEI). This that can lead to undisciplined use of natural resources.

- Calculation of an alternative energy efficiency index, normalized by the occupant total number of building occupants (as opposed to net floor area), showed that it may be a more representative parameter.

We leave the development and refinement of the concepts discussed in the qualitative limitations of the SCE section as a suggestion 
to foster thinking in the work that is already happening to improve this type of regulations throughout the EU.

\section{References}

[1] IEA, "World Energy Outlook," 2008.

[2] Ministério da Economia e da Inovação, "Decreto-Lei nº 78/2006," 2006.

[3] Ministério da Economia e da Inovação, "Decreto-Lei nº 79/2006," 2006.

[4] Ministério da Economia e da Inovação, "Decreto-Lei nº 80/2006," 2006.

[5] U.S. Department of Energy. (2009) EnergyPlus Energy Simulation Software. [Online].

http://apps1.eere.energy.gov/buildings/e nergyplus/

[6] UE, "Directive 2002/91/CE of the European Parliament and Council, 16 Dec 2002, relative to energy performance of buildings," 2002.

[7] DesignBuilder Software Ltd. (2009) DesignBuilder. [Online]. http://www.designbuilder.co.uk/

[8] INETI.
[9] JRC European Comission. (2009) Photovoltaic Geographical Information System. [Online]. http://re.jrc.ec.europa.eu/pvgis/

[10] J. S. Farinha, "O Metropolitano e a Baixa de Lisboa: condições geotécnicas e históricas," Metropolitano de Lisboa, 1995.

[11] US Green Council. LEED Rating Systems. [Online]. http://www.usgbc.org/DisplayPage.aspx ?Category|D=19

[12] BREEAM. Environmental Assessment Method . [Online]. http://www.breeam.org/

[13] X. G. Casals, "Analysis of building energy regulation and certification in Europe: Their role, limitations and differences," Energy and Buldings, pp. 381-392, 2005.

[14] Natural Works, 2007.

[15] M. S. Al-Homoud, "Computer-aided building energy analysis techniques," Building and Environment, pp. 421-423, 2001. 